\title{
Chemotherapeutic drugs sensitize human renal cell carcinoma cells to ABT-737 by a mechanism involving the Noxa-dependent inactivation of $\mathrm{Mcl}-1$ or $\mathrm{A} 1$
}

\author{
Henry Zall1 ${ }^{1}$ Arnim Weber ${ }^{4}$, Robert Besch², Niko Zantl ${ }^{3}$ and Georg Häcker*4
}

\begin{abstract}
Background: Human renal cell carcinoma (RCC) is very resistant to chemotherapy. ABT-737 is a novel inhibitor of antiapoptotic proteins of the $\mathrm{BCl}-2$ family that has shown promise in various preclinical tumour models.

Results: We here report a strong over-additive pro-apoptotic effect of ABT-737 and etoposide, vinblastine or paclitaxel but not 5-fluorouracil in cell lines from human RCC. ABT-737 showed very little activity as a single agent but killed RCC cells potently when anti-apoptotic Mcl-1 or, unexpectedly, A1 was targeted by RNAi. This potent augmentation required endogenous Noxa protein since RNAi directed against Noxa but not against Bim or Puma reduced apoptosis induction by the combination of ABT-737 and etoposide or vinblastine. At the level of mitochondria, etoposidetreatment had a similar sensitizing activity and allowed for ABT-737-induced release of cytochrome $C$.

Conclusions: Chemotherapeutic drugs can overcome protection afforded by $\mathrm{Mcl}-1$ and $\mathrm{A} 1$ through endogenous Noxa protein in RCC cells, and the combination of such drugs with ABT-737 may be a promising strategy in RCC. Strikingly, A1 emerged in RCC cell lines as a protein of similar importance as the well-established Mcl-1 in protection against apoptosis in these cells.
\end{abstract}

\section{Background}

Renal cell carcinoma is the most common (85\%) malignant tumour of the kidney. Although the disease can be cured by removal of the kidney in cases of localized disease, about $20 \%$ of patients have detectable metastatic disease at the time of diagnosis, and $20-40 \%$ of patients develop metastases following surgery. The 2 year survival of patients with metastatic disease is under $20 \%[1,2]$, reflecting the poor response of the disseminated tumour to chemo- or radiotherapy.

This resistance is at least in part the result of a low sensitivity of the tumour cells to apoptosis induction by these agents. Chemotherapeutic drugs are generally recognized as inducers of mitochondrial apoptosis, and the efficiency of this process is a determinant of the drug response [3]. Mitochondrial apoptosis is largely regulated by the Bcl-2

\footnotetext{
* Correspondence: georg.haecker@uniklinik-freiburg.de

${ }^{4}$ Institute of Medical Microbiology and Hygiene, University Freiburg, HermannHerder-Str., Freiburg, Germany

Full list of author information is available at the end of the article
}

family of proteins [4]. This family contains both pro- and anti-apoptotic members. Apoptosis is initiated by one or several proteins from the BH3-only subgroup (eight proteins that are structurally related to each other only in their short alpha-helical BH3-domain are accepted by the majority of authors although more have been proposed), which then activate the effectors Bax/Bak. The antiapoptotic proteins (Bcl-2, Bcl- $\mathrm{X}_{\mathrm{L}}, \mathrm{Bcl}-\mathrm{w}, \mathrm{Mcl}-1$ and $\mathrm{A} 1$ ) prevent this activation. Full activation of Bax or Bak results in the release of cytochrome $c$ from mitochondria, the cytosolic activation of caspases and apoptosis [3]. How the activation of Bax/Bak by $\mathrm{BH} 3$-only proteins occurs molecularly and which members of the subgroups interact during apoptosis induction is a matter of dispute [5-7].

Anti-apoptotic Bcl-2 proteins can bind BH3-only proteins through their BH3-domains although with surprisingly strongly varying affinities [8]. This has engendered the model that anti-apoptotic proteins normally keep 
Bax/Bak inactive until saturated by $\mathrm{BH} 3$-only proteins (alone or in combination), which will allow auto-activation of Bax/Bak [6]. Others favour a model where Bax/ Bak have to be activated through BH3-only proteins although this has proved difficult to show experimentally $[9,10]$. It is clear however that some BH3-only proteins can bind to all anti-apoptotic proteins (such as the BH3only proteins Bim and Puma) while for instance Bad can bind only Bcl-2, Bcl- $\mathrm{X}_{\mathrm{L}}$, Bcl-w but not Mcl-1 or A1. The opposite is the case for the BH3-only protein Noxa, whose binding appears to be restricted to Mcl-1 and A1 [8]. Extensive experimental evidence shows that the two anti-apoptotic groups of proteins, $\mathrm{Bcl}-2, \mathrm{Bcl}-\mathrm{X}_{\mathrm{L}}, \mathrm{Bcl}-\mathrm{w}$ on one hand and Mcl-1 and A1 on the other both have to be targeted to induce apoptosis [3].

Recently, feasibility of a new approach to apoptosis induction has been demonstrated in a range of tumour cells, namely the specific targeting of anti-apoptotic Bcl-2 proteins. One substance, ABT-737 has already been tested in a number of preclinical models in vitro and in animals and the orally better bioavailable derivative ABT263 is at present in clinical studies [11-13]. ABT-737 binds with high affinity to the BH3-binding cleft in Bcl-2, Bcl-X $\mathrm{L}_{\mathrm{L}}$ and Bcl-w but not Mcl-1 or A1 $[11,14]$. A number of malignancies show response to treatment with ABT737 as single agent while more are sensitive to the combination of $\mathrm{ABT}-737$ with other chemotherapeutic drugs (for review see $[15,16]$ ). The binding pattern of ABT-737 to anti-apoptotic proteins suggested that apoptosis resistance due to high expression of Bcl-2 would be overcome but the expression of $\mathrm{Mcl}-1$ or A1 would provide protection. A number of studies have investigated this resistance to ABT-737 and have found consistently that Mcl-1 can indeed confer resistance to ABT-737 while experimental approaches that down-regulate $\mathrm{Mcl}-1$ sensitize tumour cells to ABT-737 (reviewed in [16]). Since downregulation of Mcl-1 has this strong effect, A1 seems to play no role in resistance to ABT-737 and it has been said that $A 1$ is not expressed in most tumours although this may be a problem of sensitivity of A1 protein detection [14]. However, especially in haematological tumours a role of A1 has been found [17-19], and over-expression of A1 in mice has been described to contribute to tumorigenesis [20].

In RCC cells, easily detectable levels of Bcl-2 are expressed [21], and some association of high Bcl-2expression with a poor prognosis in $\mathrm{RCC}$ has been described [22]. We have found recently that the expression of the BH3-only protein Bim was reduced in RCC [23], which may contribute to low drug sensitivity in this tumour entity. Although the binding capacity of Bim in terms of anti-apoptotic Bcl-2 proteins is broader than that of ABT-737, there is the chance that ABT-737 will nevertheless overcome apoptosis resistance of RCC when combined with other chemotherapeutic drugs, for instance by releasing the little Bim there is from its sequestration to anti-apoptotic $\mathrm{Bcl}-2$ proteins. We therefore undertook this study where we tested for augmentation of ABT-737-killing by drugs in use as chemotherapeutic agents against RCC.

In cell lines in vitro, ABT-737 sensitized RCC cells strongly to apoptosis induction by etoposide, paclitaxel and vinblastine but not 5-fluorouracil (5-FU). In analyzing the contribution of Bcl- 2 family proteins we noticed that endogenous Noxa protein was required for this sensitization, suggesting that neutralization of Mcl-1 or A1 was achieved only through Noxa. Reduction of Mcl-1 expression by RNAi rendered RCC cells sensitive to ABT737 in the absence of additional stimuli. More surprisingly, A1-specific RNAi had a similar sensitizing effect on RCC cells. RCC cells can thus be killed efficiently if the 'Bcl' group of anti-apoptotic proteins $\left(\mathrm{Bcl}-2, \mathrm{Bcl}-\mathrm{X}_{\mathrm{L}}, \mathrm{Bcl}-\right.$ w) are targeted by ABT-737 and the group consisting of Mcl-1 and A1 by endogenous Noxa protein.

\section{Results}

ABT-737 enhances apoptosis induced by vinblastine, paclitaxel and etoposide but not 5-FU in RCC lines

We tested four patient-derived clear cell RCC cell lines for their sensitivity to ABT-737. ABT-737 on its own was almost completely inactive. As noted previously, little apoptosis was induced by any of the chemotherapeutic drugs used. However, there was a strong, more than additive pro-apoptotic effect of ABT-737 plus three of the four other drugs tested. This effect was strongest for etoposide but still substantial for vinblastine and paclitaxel (Figure 1; Additional file 1, Figure S1A and B). No such effect was seen for the combination of 5-FU and ABT-737 in any of the lines tested, even at later time points where 5-FU induced considerable apoptosis on its own (Additional file 1, Figure S1D). No more than additive induction of apoptosis (as measured by staining for active caspase-3) or cell death (detected as PI-staining) was observed for a range of concentrations of 5-FU and ABT-737 (Figure 1; Additional file 1, Figure S1A, C and data not shown). Staining for annexin $\mathrm{V}$-binding gave similar results as staining for active caspase-3 (Additional file 1, Figure S1B). Cell death induced by combination treatment was caspase-dependent as it was blocked by the caspase-inhibitor zVAD-fmk (Additional file 1, Figure S1A). ABT-737 thus can sensitize RCC cell lines for treatment with vinblastine, paclitaxel or etoposide.

\section{Etoposide sensitizes for ABT-737 at the level of mitochondria}

ABT-737 acts on Bcl-2-like proteins, which are at least predominantly localized on mitochondria. It is assumed 


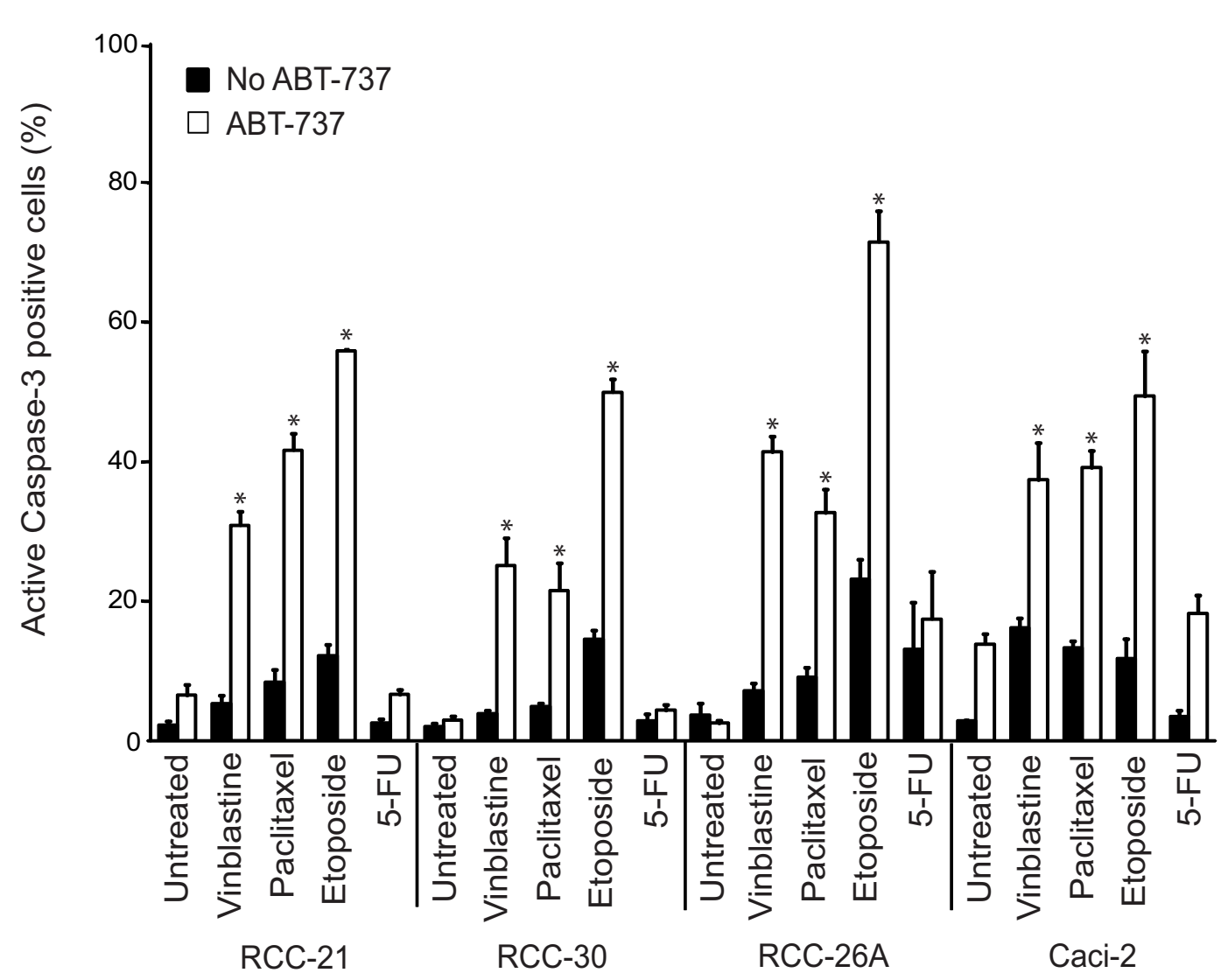

Figure 1 Potent augmentation of ABT-737-killing by chemotherapeutic drugs.Cells from clear cell RCC lines 21, 30, 26A and Caci-2 were treated with $1 \mu$ M ABT-737, $100 \mathrm{nM}$ vinblastine, $200 \mathrm{nM}$ paclitaxel, $200 \mu \mathrm{M}$ etoposide, $1 \mathrm{mM}$ 5-FU or with the combination of ABT-737 plus chemotherapeutic drugs. Apoptosis was quantified by staining for activated caspase-3 at $24 \mathrm{~h}$. Values represent the mean/SEM of at least three independent experiments. Note that ABT-737 on its own induced significant apoptosis in the RCC cell line Caci-2. The difference between ABT-737 alone and ABT-737 + 5 -FU was not statistically significant ( ${ }^{*} P<0.04$, single treatment versus combination treatment).

that cytochrome $c$ is released from mitochondria once all anti-apoptotic Bcl-2 family members have been neutralized [6] or when certain BH3-only proteins are liberated to activate Bax or Bak [9] (for a recent discussion see [24]), and treatment of isolated mitochondria or permeabilized cells with a peptide encompassing the Bim BH3domain can initiate this release [5]. To obtain further evidence of the collaboration of ABT-737 and etoposide, we exposed permeabilized RCC cells that had been pretreated with etoposide to Bim-peptide or ABT-737. As shown in Figure 2, Bim-peptide but not ABT-737 induced the release of cytochrome $c$ from untreated cells from the cell line RCC-26A. This is in accordance with results in other cellular models and suggests that Bim-peptide was able to induce cytochrome $c$-release because it neutralized all Bcl-2-like proteins while ABT-737 spares Mcl-1 and $\mathrm{A} 1$ and therefore is inactive on its own; alternatively, the Bim-peptide may directly activate Bax or Bak. However, in cells that had been pre-treated with etoposide for
$24 \mathrm{~h}$ and then permeabilized, ABT-737 was active in releasing cytochrome $c$ (Figure 2). This suggests that etoposide-treatment had the effect of neutralizing Mcl-1 and/or A1, thereby sensitizing mitochondria for ABT737. In line with the results obtained with intact cells, 5FU failed to sensitize permeabilized cells to ABT-737induced cytochrome $c$-release (Figure 2). The results therefore suggest that etoposide but not 5-FU can neutralize Mcl-1 and/or A1, leaving mitochondria sensitive to ABT-737.

\section{Noxa levels during treatment of RCC cells}

Although Mcl-1 can also bind Bim and Puma with high affinity [8], evidence for regulation of Mcl-1 activity through Noxa has been presented several times [25]. Further, etoposide-treatment seemed able to neutralize Mcl1 and/or A1 but had only low apoptosis-inducing activity on its own, suggesting that other Bcl-2 proteins were not targeted. This indicated a role of Noxa in the treatment of 
A
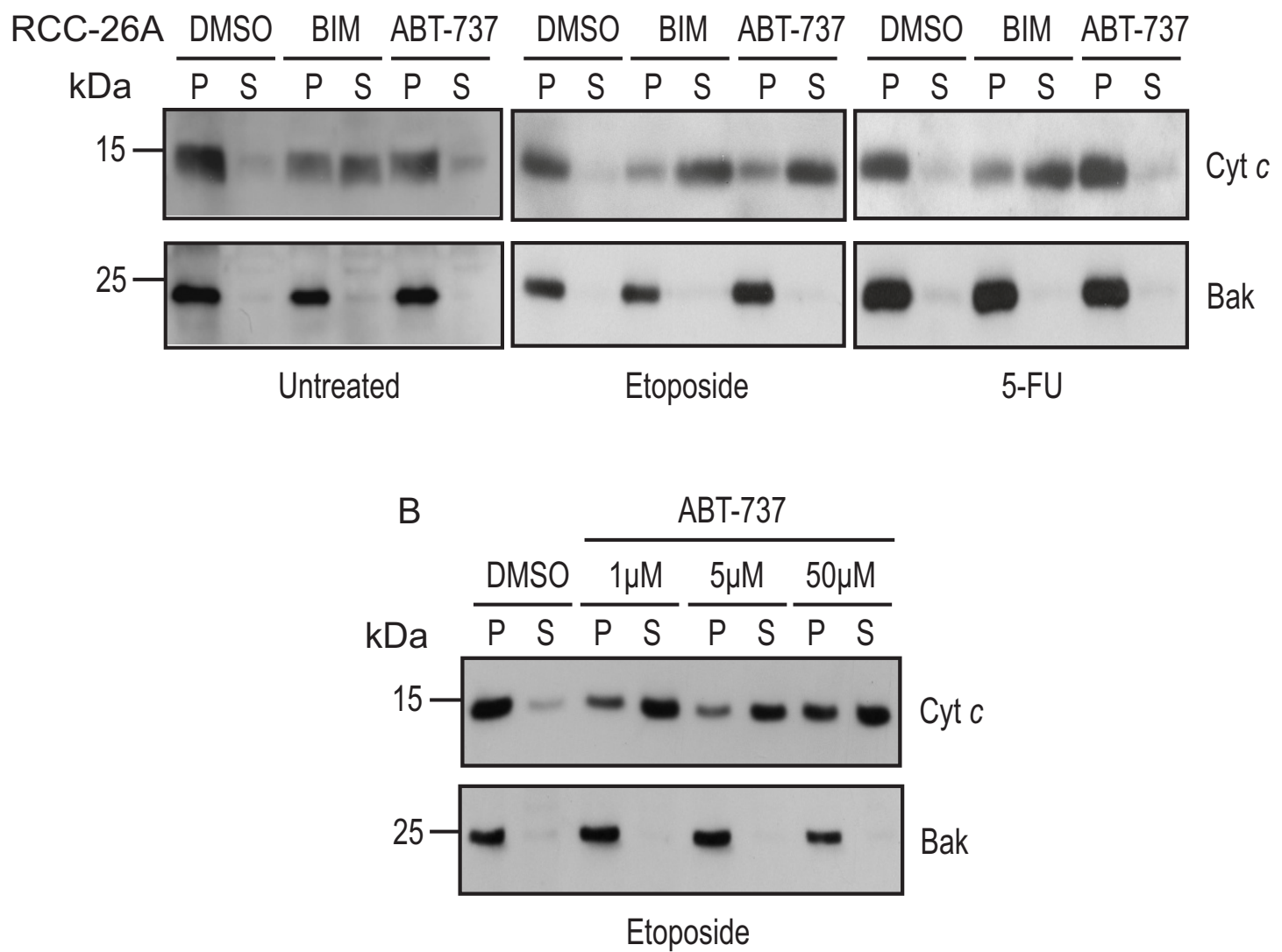

Figure 2 Etoposide sensitizes RCC cells for cytochrome c-release by ABT-737 from mitochondria.(A), (B), RCC-26A cells were cultured in complete medium (untreated) or treated with $200 \mu$ M etoposide or $1 \mathrm{mM} \mathrm{5-FU} \mathrm{for} 24 \mathrm{~h}$. Cells were permeabilized with $200 \mu \mathrm{g} / \mathrm{ml}$ digitonin in the presence of solvent (DMSO, control), a peptide encompassing the Bim BH3-domain (100 $\mu \mathrm{M}$ ) or ABT-737 (concentrations as shown, $50 \mu \mathrm{M}$ in $\mathbf{A}$ ). Reactions were separated into supernatants and insoluble pellets and fractions were analyzed by Western blotting for cytochrome $c$. Membranes were re-probed with a Bak-specific antibody as mitochondrial marker. P, pellet fractions, containing cytochrome c retained by mitochondria. S, supernatant fractions, containing released cytochrome $c$.

RCC cells with chemotherapeutic agents since Noxa is the only BH3-only protein whose binding is limited to Mcl-1 and A1. We therefore assessed Noxa and Mcl-1 levels in RCC cell lines during treatment with these drugs. As shown in Figure 3, Noxa protein was undetectable in two and very lowly expressed in the other two cell lines used. In all cell lines, etoposide induced Noxa protein levels most strongly of the drugs tested but only in one cell line Mcl-1 was lost concomitantly (RCC-26A). In two cell lines, the other drugs failed to induce detectable levels of Noxa while in the other two all of them caused detectable induction. In these two cell lines, there was no clear difference between the drugs that potently augment ABT-737-killing (vinblastine, paclitaxel) and 5-FU, which did not have this effect. Although the results thus suggest a participation of Noxa, a number of points are not explained on the basis of these expression levels.
Loss of expression of either Mcl-1 or A1 sensitizes RCC cells to apoptosis induced by ABT-737

As discussed above, the results suggested that etoposide and other drugs were able functionally to eliminate Mcl-1 and/or A1, enabling ABT-737 to induce apoptosis. In a number of cells it has been demonstrated that it is the expression of Mcl-1 that determines resistance to ABT737 while $\mathrm{A} 1$ has been suggested not to be expressed by most tumours [14]. We decided to knock down Mcl-1 and $\mathrm{A} 1$ individually to test for their contributions to resistance to ABT-737. Clear although incomplete reduction of Mcl-1 protein by transfection with Mcl-1-specific siRNA was achieved in the three RCC cell lines used as well as in one cell line engineered stably to express Mcl-1specific shRNA (Additional file 1, Figure S2A). Only very little A1 protein was detectable by Western blotting, which may be the result of low levels of expression or of 


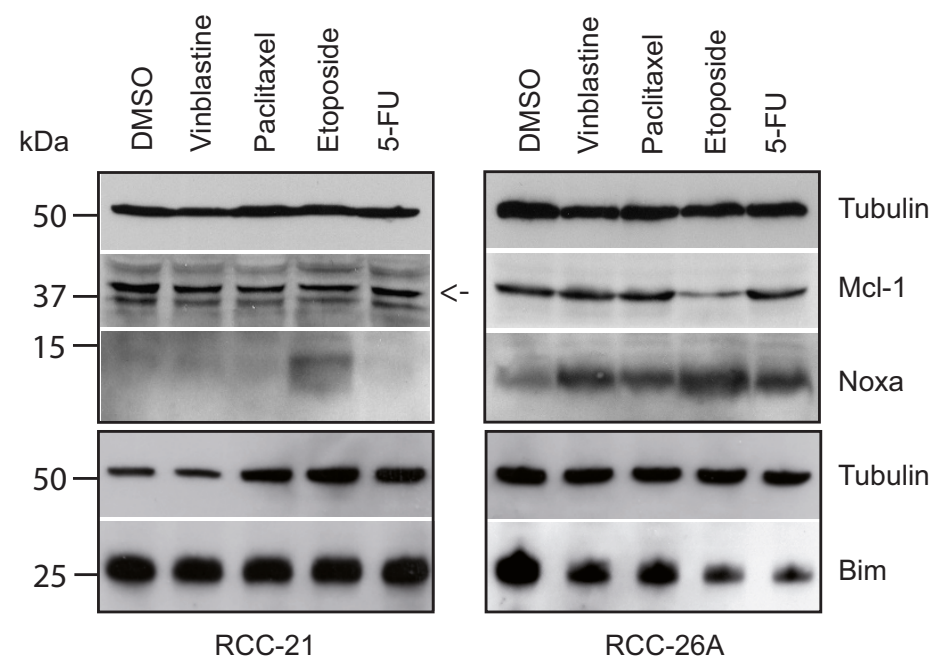

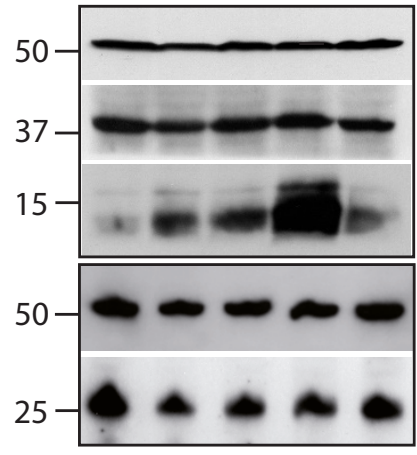

RCC-30

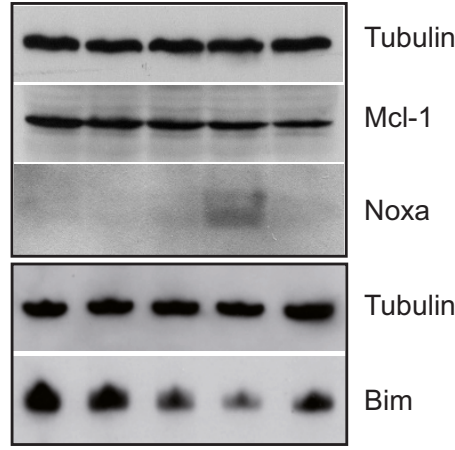

Caci-2
RCC-21



Etoposide
RCC-26A

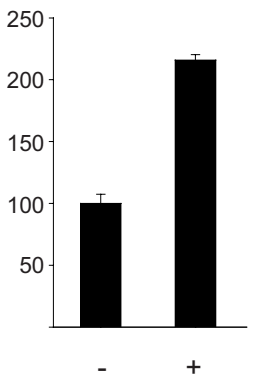

Caci-2

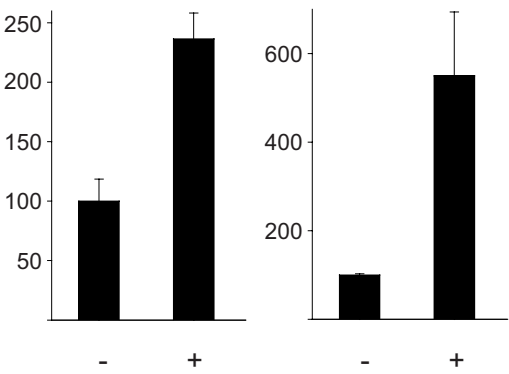

Figure 3 Expression levels of Noxa, Mcl-1, Bim and A1 in RCC lines treated with chemotherapeutic drugs.Cells from RCC cell lines $21,26 \mathrm{~A}, 30$ and Caci-2 were treated for $24 \mathrm{~h}$ with the indicated drugs (100 nM vinblastine, $200 \mathrm{nM}$ paclitaxel, $200 \mu \mathrm{M}$ etoposide, $1 \mathrm{mM}$ 5-FU). Total cell lysates were assayed for Noxa, Mcl-1 and Bim levels by Western blot analysis. Tubulin served as a loading control. The immunoblots shown here are representatives of three separate experiments. The mRNA-levels of A1 were measured by quantitative RT-PCR in cells that had been treated for $24 \mathrm{~h}$ with etoposide or not. The mean values of untreated controls were normalized to 100\%. Data are mean/SEM from three separate experiments. 
low sensitivity of the available antibodies, and we failed to detect A1 protein in two of the RCC cell lines despite clear mRNA expression (Additional file 1, Figure S2B, C). However, A1 mRNA was easily detectable, and a good reduction was achieved by transfection with specific siRNA (Additional file 1, Figure S2C; in a melanoma cell line expressing detectable protein levels of A1, siRNA against A1 gave a good reduction, see Additional file 1, Figure S2B). Knock-down of Mcl-1-expression strongly sensitized RCC cells to ABT-737 (Figure 4A), adding RCC to the list of cell types where the expression levels of Mcl1 determine susceptibility to ABT-737-induced apoptosis. Importantly, knock-down of A1 had a similar sensitizing effect (Figure 4B). There was even noticeable cell death induction by mere knock-down of $\mathrm{A} 1$ in the absence of additional stimuli (Figure 4B). A second siRNA directed against a separate site in the A1-mRNA had a similar sensitizing effect in the RCC cell line tested (RCC-26A, Additional file 1, Figure S3). The RCC-26A cell line stably carrying an anti-Mcl-1 shRNA construct was also sensitive to ABT-737 (Figure 4C). Additional knock-down of A1 by transient transfection with siRNA caused further sensitization for ABT-737 treatment (Figure 4D). These data indicate that resistance to ABT-737 in RCC cells is determined not only by Mcl-1 but also by expression levels of A1, and both proteins may fulfil similar functions.

\section{Potent augmentation of ABT-737-killing by etoposide or vinblastine requires Noxa}

Although the data above show an induction of Noxa upon treatment with chemotherapeutic drugs, Noxa seemed unable to cause $\mathrm{Mcl}-1$ degradation in most cases, which could indicate that Noxa was not involved in apoptosis induced by combination treatments including ABT-737. Further, the BH3-only proteins Bim and Puma can also bind Mcl-1 and A1 [8] and might therefore be responsible for their neutralisation. To identify the $\mathrm{BH}$-only protein that causes this effect, we knocked down Bim, Puma and Noxa individually by transfection with specific siRNA. As shown in Additional file 1, Figure S4, the expression of the target proteins was substantially reduced upon transfection with the relevant siRNA (since basal Noxa protein levels were difficult to detect, Noxa knock-down was here done in the presence of etoposide, Additional file 1, Figure $\mathrm{S} 4 \mathrm{C}$ ). As shown in Figure $5 \mathrm{~A}$ and $5 \mathrm{~B}$, no reduction of cell death was seen by the knock-down of Bim or Puma when RCC-26A or RCC-30 cells were treated with the combination of etoposide and ABT-737. However, Noxaspecific siRNA significantly reduced cell death induction by this combination. Noxa- but not Bim- or Puma-specific siRNA also inhibited cell death induced by the combination of vinblastine and ABT-737 in RCC-26A (Figure
5A) and RCC-30 (Figure 5B; for the comparative expression of Bcl-2 family proteins in RCC-26A and 30 see Additional file 1, Figure S4D). These data strongly suggest that the neutralisation of either Mcl-1 or A1 by Noxa is the effect through which chemotherapeutic drugs sensitize RCC cells to apoptosis induction by ABT-737.

These results showed the integrity of an axis where Noxa regulates the activity of Mcl-1 and A1 in RCC. Since this axis can also be used by proteasome inhibitors, we tested whether proteasome inhibition could also sensitize RCC cells to ABT-737-induced apoptosis. As shown in Additional file 1, Figure S5A, the proteasome inhibitor MG132 increased the levels of Mcl-1 and Noxa and blocked the etoposide-induced loss of Mcl-1 in RCC-26A cells. The loss of Mcl-1 during treatment with etoposide still occurred in the presence of zVAD-fmk, indicating that this loss was not due to cell death (Additional file 1, Figure S5B). MG132 further sensitized the cells for apoptosis induction by ABT-737 (Additional file 1, Figure $\mathrm{S} 5 \mathrm{C})$. Although etoposide induced p53-protein, the induction of Noxa by etoposide was independent of p53 (Additional file 1, Figure S5D). One possible explanation for this is that Mcl-1 (and perhaps A1) protein were stabilised but still inhibited by Noxa-binding.

\section{Discussion}

The results of this study show that in vitro ABT-737-killing of RCC-cells is potently augmented by etoposide, vinblastine and paclitaxel but is surprisingly not enhanced by 5 -FU. In the active combinations, the contribution of the 'traditional' chemotherapeutic drugs was the (at least in part Noxa-dependent) neutralization of Mcl-1 and/or A1 at mitochondria. Down-regulation of Mcl-1 sensitized RCC cells to ABT-737 induced apoptosis. Unexpectedly, siRNA-targeting of A1 had a very similar effect and loss of both proteins produced an additive result, suggesting that the total sum of Mcl-1 and A1 expressed in RCC cells is required to maintain viability in the presence of $\mathrm{ABT}$ 737.

We had previously found that the expression levels of Bim correlated with RCC-sensitivity to apoptosis, suggesting that the chemotherapeutic drugs used in part worked by activating Bim [23]. ABT-737 overcame this requirement as its pro-apoptotic activity was potently augmented by Mcl-1- or A1-knockdown. This is surprising as it suggests that Bim (in the absence of ABT-737) is activated but unable to neutralize Mcl-1, despite the high affinity of the Bim BH3-domain for Mcl-1 [8]. However, recent results in melanoma demonstrate the same effect, namely that the requirement for Bim is overcome by ABT-737 [26]. At least these relatively low levels of Bim therefore seem not to be able to antagonize the protection afforded by Mcl-1. 

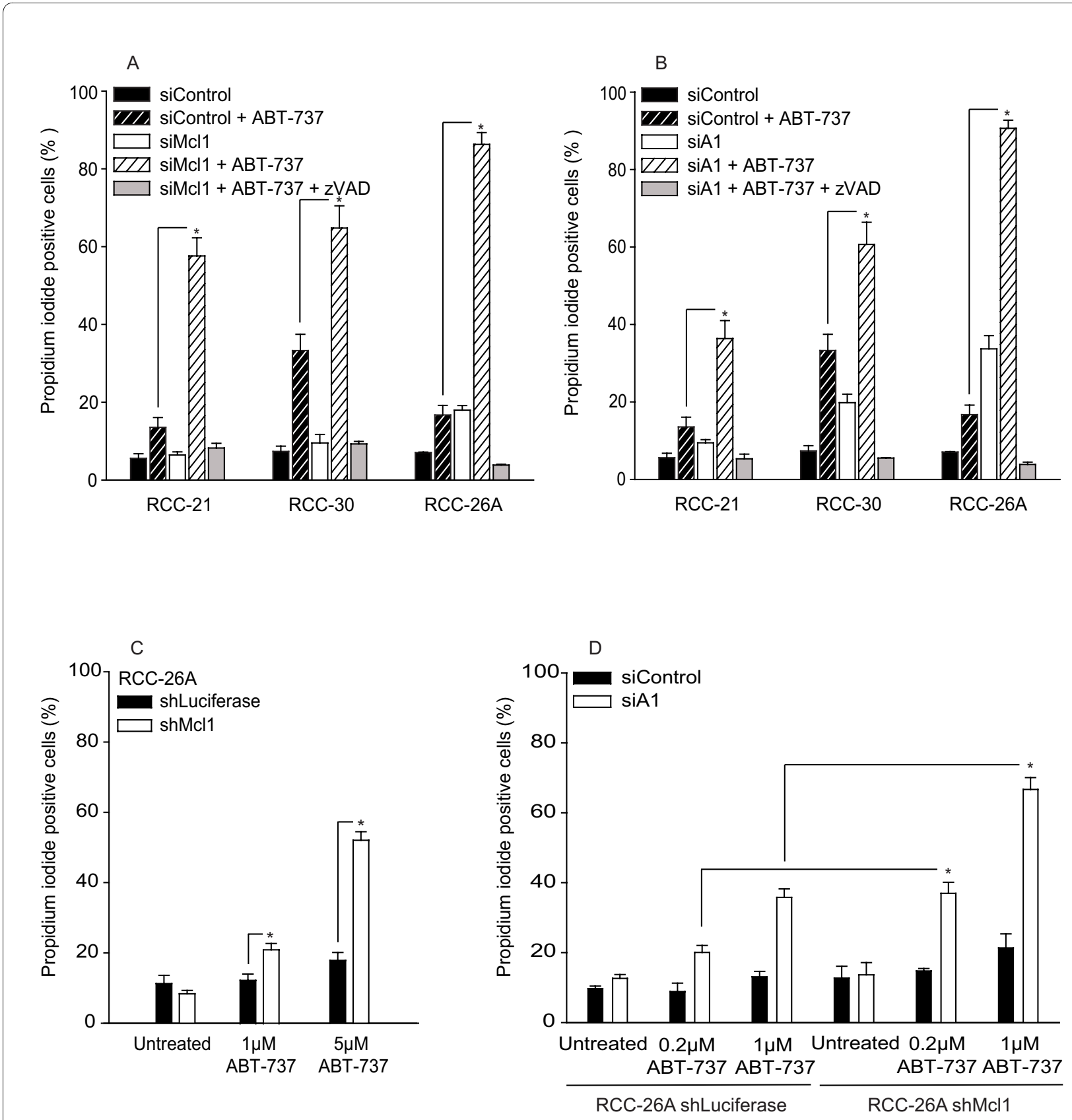

Figure 4 Loss of Mcl-1 or A1 sensitizes RCC cells to apoptosis induced by ABT-737. Cells from RCC cell lines 21, 26A and 30 were transfected with $20 \mathrm{nM}$ of a control siRNA or with siRNA specific for Mcl-1 (A) or A1 (siRNA 441) (B). $48 \mathrm{~h}$ later, cells were treated with $5 \mu \mathrm{M}$ ABT-737 for $24 \mathrm{~h}$ and cell death was measured by propidium iodide staining. In some samples $100 \mu \mathrm{M}$ zVAD-fmk was added $1 \mathrm{~h}$ prior to treatment with ABT-737. (C), RCC cell line 26A stably expressing Luciferase (control) or Mcl-1-specific shRNA were treated with $1 \mu \mathrm{M}$ and $5 \mu \mathrm{M}$ ABT-737 for $24 \mathrm{~h}$ and cell death was measured by propidium iodide staining. (D), Cells from RCC-26A shLuciferase and shMcl-1 were transfected with control siRNA or A1-specific siRNA (siRNA 441). $24 \mathrm{~h}$ post transfection cells were treated with $0.2 \mu \mathrm{M}$ and $1 \mu \mathrm{M}$ ABT-737 and stained with propidium iodide $24 \mathrm{~h}$ later. Data are mean/SEM of three independent experiments ( ${ }^{*} P<0.04$, control siRNA versus Mcl-1 siRNA and A1 siRNA; shLuciferase versus shMcl-1).

Although ABT-737 is active as a single agent in some cases of tumour cells, it much more commonly requires a combination partner for efficient induction of apoptosis $[27,28]$. It is clear that protection through high expression levels of Bcl-2 is easily overcome by ABT-737 while expression of Mcl-1 protects cells against ABT-737 [14], as does mouse A1 [20]. The main contribution of any combination partner, such as genotoxic drugs commonly used in cancer therapy, must therefore be the neutralisation of Mcl-1 and/or A1. This is clinically relevant: the 

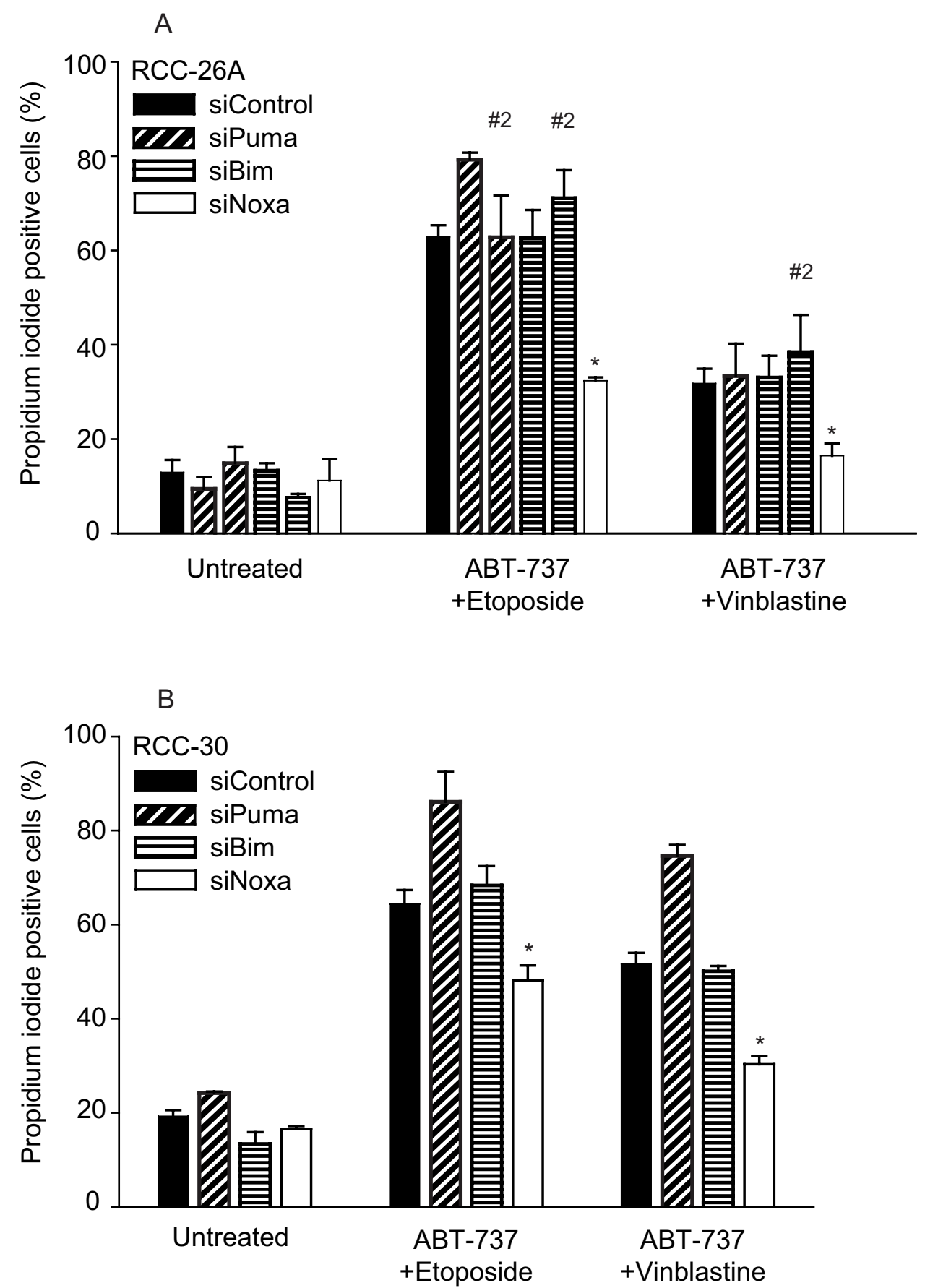

Figure $\mathbf{5}$ Noxa but not Bim or Puma is required for full synergism between ABT-737 and etoposide or vinblastine.Cells from the RCC cell line 26A (A) or 30 (B) were transfected with 20 nM of the indicated siRNAs (Bim, Puma, Noxa or control; in some experiments a second sequence targeting Bim and Puma has been included, \#2). $48 \mathrm{~h}$ later, cells were treated with ABT-737 (1 $\mu \mathrm{M})$ plus etoposide $(200 \mu \mathrm{M})$ or vinblastine (100 nM) as indicated. Cell death was determined by propidium iodide staining $24 \mathrm{~h}$ later. Values are mean/SEM of at least three independent experiments $(* P<0.03 ;$ control siRNA versus Noxa siRNA). 
results obtained in pre-clinical studies so far make it likely that the greatest success of ABT-737/ABT-263 will be in combination with chemotherapeutic drugs such as the ones in common use. However, the most potent combination partner will not necessarily be the drug that is most potent on its own but probably the one that most potently neutralizes Mcl-1 and A1. Why 5-FU was unable to cooperate with ABT-737 is unclear. 5-FU and vinblastine or paclitaxel seemed similar in their activity to induce Noxa-levels, and it would therefore be expected that they are similar in terms of sensitizing RCC cells to ABT-737. It is possible that additional mechanisms exist that control Mcl-1 and A1-inactivation consecutive to Noxa-induction but the existence of such mechanisms is completely speculative. One possibility is that Noxa is sequestered, perhaps by co-induction of an additional protein, and cannot actually bind to Mcl-1 or A1. It is further possible that 5-FU, while inducing Noxa, also increases the levels of Mcl-1/A1, perhaps by stabilizing the protein, which might counteract the pro-apoptotic effect of Noxa. More detailed studies will be required to clarify this.

In RCC, etoposide and vinblastine required endogenous Noxa for the potent augmentation of ABT-737-killing. Noxa was first described as a protein induced by phorbol-ester treatment [29]. Its function as a pro-apoptotic protein was first described as a transcriptional target of p53 [30]. Noxa can also be a transcriptional target of interferon-signalling and viral infection [31,32]. Noxa is further induced by treatment with proteasome inhibitors although this has, in melanoma, been suggested to be an indirect effect through the activation of c-myc [33]. RCC cells have usually wt p53 but p53 seems to be non-functional due to a dominant negative inhibitor [34,35]. Etoposide was found to induce p53 although the knockdown of p53 had very little effect on Noxa-induction in RCC, consistent with the concept that RCC do not have functional p53. The c-myc pathway has recently been suggested to be activated in clear cell RCC although Noxa was not identified as an up-regulated gene in that study [36]. How Noxa is activated by the drugs used here is therefore not clear.

It was surprising to note that Mcl-1 is not necessarily degraded upon treatment of RCC cell lines with agents that sensitize for ABT-737; the only situation where we observed such a decrease was treatment of one of the cell lines with etoposide. However, even in situations where Mcl-1 was not degraded Noxa was clearly involved in sensitization towards ABT-737, as shown by knock-down experiments. It has been suggested that Mcl-1 has to be degraded by the proteasome upon Noxa binding in order to be inactivated, and inhibition of the proteasome prevented the loss of Mcl-1 function [37]. This is an intriguing observation but molecularly unclear: why does Noxa when bound to Mcl-1 not suffice to neutralize its function? Moreover, there are now a number of reports showing that proteasome inhibitors can sensitize tumour cells to ABT-737, which indicates that they neutralize Mcl-1. We have found the same sensitization to ABT-737 by MG132 in our RCC cell lines in this study. Molecular details are uncertain but it seems clear on the basis of our results that Mcl-1 does not have to be degraded for the sensitization of RCC cells to ABT-737. Since targeting of A1 was also able to sensitize RCC cells, it is a possibility that the primary function of Noxa in these cases was to neutralize the function of A1 rather than Mcl-1.

A1 is a less well-investigated member of the established anti-apoptotic Bcl-2 protein group. A1 may not be expressed, at least not at high levels in many cells [14,37]. It is also possible that A1 has a very high turnover, as indeed has been suggested in a previous study. A1 mRNA was easily detectable in the cell lines we tested although we were able to detect only an uncertain signal by Western blotting. It is therefore possible that the main regulation of A1 occurs by regulating its stability. In malignant B cells, A1 has recently been described to play important roles in regulating cell survival $[17,18]$. As far as we know, no such role has been found in solid tumours. Intriguingly, the knock-down of either Mcl-1 or A1 was sufficient to sensitize RCC cells to ABT-737, suggesting that both proteins are necessary for survival in the presence of ABT-737. This is surprising since a distinct molecular role of Mcl-1 has been suggested, namely the sequestration of Bak. In that study, Bak was found to be sequestrated by Mcl-1 and by $\mathrm{Bcl}-\mathrm{X}_{\mathrm{L}}$ while $\mathrm{A} 1$ was unable to fulfil this function [37] although a more recent study found that A1 could interact with and inhibit Bak [19]. Clearly, more work is required to clarify this.

In summary, both anti-apoptotic Bcl-2 proteins Mcl-1 and $\mathrm{A} 1$ determine the level of resistance to ABT-737 in RCC cells, and this layer of protection is disrupted by etoposide, vinblastine and probably other drugs. To understand tumour cell apoptosis in more detail and to devise rational strategies to induce apoptosis therapeutically, a better understanding of A1 function may be expected to be helpful.

\section{Methods}

\section{Cell lines and materials}

Human, patient-derived clear-cell renal cell carcinoma lines RCC-21, RCC-26A, RCC-30 and Caci-2 were from the German Cancer Research Centre, Heidelberg, Germany. Cells were maintained in RPMI-1640, supplemented with $10 \%$ foetal calf serum (FCS), $100 \mathrm{U} / \mathrm{ml}$ penicillin and $0.1 \mu \mathrm{g} / \mathrm{ml}$ streptomycin (PAA, Berlin, Germany) at $5 \% \mathrm{CO}_{2}, 37^{\circ} \mathrm{C}$ humidified atmosphere. Etoposide, paclitaxel, vinblastine and 5-fluoruracil were obtained from Sigma-Aldrich (Steinheim, Germany). 
ABT-737 was kindly provided by Dr. Saul Rosenberg and Dr. Steve Elmore (Abbott Laboratories, Abbott Park, NJ, USA).

\section{Detection of apoptosis and cell death}

Cells from RCC lines were treated with the indicated drugs, harvested and washed twice in PBS, following staining with propidium iodide $(5 \mu \mathrm{g} / \mathrm{ml})$ in PBS or annexin $\mathrm{V}$ in binding buffer (10 mM Hepes pH 7.4, 140 $\mathrm{mM} \mathrm{NaCl}$ and $2.5 \mathrm{mM} \mathrm{CaCl}_{2}$ ) and analysed within 10 min. by flow cytometry (FACS Calibur, Becton Dickinson, Franklin Lakes, NJ, USA). For detection of apoptosis, cells were fixed in 4\% paraformaldehyde in PBS for 10 min. at room temperature and stained with monoclonal anti-active-caspase-3 antibody (clone C92-605, BD Pharmingen) in permeabilisation buffer $(0.5 \%$ BSA and $0.75 \%$ saponin (Sigma-Aldrich) in PBS). Cells were washed in permeabilisation buffer and stained with FITC-conjugated anti-rabbit IgG secondary antibody (Dianova, Hamburg, Germany). Flow cytometric analysis was performed using a FACS Calibur (Becton Dickinson). In some experiments cells were incubated with $100 \mu \mathrm{M}$ zVAD-fmk (Bachem, Heidelberg, Germany) $1 \mathrm{~h}$ prior to cell death induction.

\section{Immunoblotting}

Cells were lysed in buffer containing 1\% Triton X-100, 50 $\mathrm{mM}$ Tris- $\mathrm{HCl}, \mathrm{pH}$ 7.4, $150 \mathrm{mM} \mathrm{NaCl}, 1 \mathrm{mM}$ EDTA and protease inhibitor cocktail (Roche, Mannheim, Germany). Equal amounts of protein extracts were subjected to SDS-PAGE and transferred to nitrocellulose. Equal loading was confirmed by detection of tubulin using a specific antibody (clone DM 18, Sigma). Membranes were probed with antibodies directed against $\mathrm{Bcl}-2$ (clone

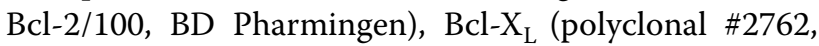
Cell Signaling, Danvers, MA, USA), Mcl-1, cytochrome $c$ (clone 22 and clone 7H8.2C12, BD Pharmingen,), Noxa (clone 114C307.1, Alexis, PA, USA,), Bim (polyclonal, B7929, Sigma), Bax, Bak (polyclonal, NT \#06-499 and polyclonal, NT \#06-536, Upstate, Lake Placid, NY, USA), Bcl-w (clone 31H4, \#2724; Cell Signaling), Puma, Bfl-1/ A1 (polyclonal \#4976 and polyclonal \#4647, Cell Signaling) and p53 (clone 1C12, Cell Signaling). Secondary antibodies were horseradish peroxidase conjugated antimouse IgG or anti-rabbit IgG antibodies (Sigma). Proteins were visualized using an enhanced chemiluminescence detection system (GE Healthcare, Buckinghamshire, UK).

\section{RNAi and quantitative reverse transcriptase PCR}

Cells from RCC lines were transfected with $20 \mathrm{nM}$ of siRNA (depicted is the 19 nt portion in the sense strand of the targeted mRNA) specific for human Mcl-1 (5'-
GGUUUGGCAUAUCUAAUAA-3'), Bfl-1/A1 (441 5'GGAAGAAUUGUAACCAU-3' and 511 5'-CGGAUGUGGAUACCUAUAA-3'), Bim (5'-GGAAGAAUUGUAACCAUAU-3' and \#2 5'-CCACUAUCUCAGU GCAAUG-30), Puma (5'-CCGAGAUGGAGCCCAAUUA-3' and \#2 5'-CCUGGAGGGUCCUGUACAA-3'), Noxa (5'-AGUCGAGUGUGCUACUCAA-3') or p53 (5'GUACCACCAUCCACUACAA-3') and a control siRNA (5'-GCGCAUUCCAGCUUACGUA-3'), containing a random sequence that does not match a sequence within the human or murine genome, using Lipofectamine RNAiMAX reagent according to the manufacturer's instructions (Invitrogen, Carlsbad, CA, USA). For generation of RCC cell line 26A stably expressing Mcl-1-specific shRNA, RNAi sequences targeting Mcl-1 (5'-ACGCGGUAAUCGGACUCAA-3') and Luciferase mRNA (5'GUGCGCUGCUGGUGCCAAC-3') were cloned in the GFP-expressing lentiviral vector pLVTHM (Dr. Didier Trono, Lausanne). Production of lentiviral particles was done by transfecting 293 FT cells (Invitrogen) together with packaging vectors pMD2.G and psPAX2 (Dr. Didier Trono, Lausanne). At $48 \mathrm{~h}$ post transfection with siRNA, cells were assayed for gene knockdown or were used for further experiments. Total RNA was extracted from RCC lines after siRNA knockdown using RNeasy mini kit (Qiagen, Hilden, Germany) and analysed by quantitative RTPCR. RNA $(1 \mu \mathrm{g})$ was reverse transcribed using Expand Reverse Transcriptase and poly (dT) oligonucleotide (Roche) according to the manufacturer's protocol. Quantitative PCR was performed using the LightCycler TaqMan Master Kit together with the Universal ProbeLibrary system (Roche). Relative gene expression is expressed as the ratio of the expression level of the gene of interest to that of hypoxanthine-phosphoribosyl-transferase (HPRT) RNA determined in the same sample.

\section{Cytochrome c-release assay}

Untreated or treated cells from the RCC-26A line $\left(2 \times 10^{5}\right.$ cells per sample) were harvested and permeabilised in sample buffer (20 mM HEPES pH 7.2, $100 \mathrm{mM} \mathrm{KCl,} 5$ mM MgCl2, 1 mM EDTA, 1 mM EGTA, 250 mM sucrose and protease inhibitor cocktail (Roche)), containing 200 $\mu \mathrm{g} / \mathrm{ml}$ digitonin (Sigma-Aldrich). Cells were incubated for $60 \mathrm{~min}$. at $30^{\circ} \mathrm{C}$ in the presence of $\mathrm{BH} 3$-only oligopeptide Bim $(100 \mu \mathrm{M})$ or ABT-737 $(1 \mu \mathrm{M}, 5 \mu \mathrm{M}$ and $50 \mu \mathrm{M})$. Bim-peptide (sequence MRPEIWIAQERRRIGDEFNA) was synthesized at Biosynthan GmbH (Berlin, Germany). Cells were then centrifuged for $10 \mathrm{~min}$. at $13000 \times \mathrm{g}$ to separate them into pellet and supernatant fractions. Samples were adjusted to equivalent volumes with $4 \times$ SDS sample loading buffer and were subjected to immunoblotting. 


\section{Additional material}

Additional file 1 Supplementary figures 1-5. Figure S1 - Potent augmentation of ABT-737-killing by chemotherapeutic drugs requires caspases. Figure S2 - Efficiency of the targeting of Mcl-1 or A1 by RNAi. Figure S3 A1-targeting by two different siRNAs sensitizes RCC-26A cells to apoptosis induced by ABT-737. Figure S4 - Synergism between ABT-737 and etoposide or vinblastine requires Noxa. Figure S5 - MG-132 increases the levels of MCl-1 and Noxa in the RCC-26A cell line and sensitizes for ABT-737 induced apoptosis.

\section{Abbreviations}

A1: $B$ cell leukemia/lymphoma 2 related protein $A 1 ; B a d: B C l-2$-antagonist of cell death; Bak: $\mathrm{BCl}-2$-antagonist/killer; Bax: $\mathrm{BCl}-2$ associated $\times$ protein; $\mathrm{BCl}-2$ : $\mathrm{B}$ cell leukemia/lymphoma 2; BCl-X: BCl-2-like 1; BCl-w: BCl-2-like 2; BH3: BCl-2 homolgy domain 3; Bim: $\mathrm{BCl}-2$ interacting mediator of cell death; $\mathrm{BSA}$ : bovine serum albumin; $\mathrm{CaCl}_{2}$ : calcium chloride; $\mathrm{CCRCC}$ : clear cell renal cell carcinoma; c-myc: cellular myelocytomatosis viral oncogene homolog; Cyt c: cytochrome c; DMSO: dimethylsulfoxide; EDTA: ethylene diamine tetraacetic acid; EGTA: ethylene glycol tetraacetic acid; FITC: fluorescein-isothiocyanate; 5-FU: 5-fluoruracil; Hepes: 4-(2-hydroxyethyl)-1-piperazineethanesulfonic acid; IgG: immunoglobulin $\mathrm{G}$; $\mathrm{KCL}$ : potassium chloride; $\mathrm{MgCl}_{2}$ : magnesium chloride; $\mathrm{MCl}-1$ : myeloid cell leukemia sequence 1; NaCl: sodium chloride; Noxa: (Latin for damage) phorbol-12-myristate-13-acetate-induced protein 1; p53: transformation related protein 53; PBS: phosphate-buffered saline; PI: propidium iodide; Puma: p53-upregulated modulator of apoptosis; RCC: renal cell carcinoma; RNA: ribonucleic acid; mRNA: messenger ribonucleic acid; RNAi: ribonucleic acid interference; shRNA: short hairpin ribonucleic acid; siRNA: small interfering ribonucleic acid; RT-PCR: reverse transcriptase polymerase chain reaction; SDSPAGE: sodium dodecyl sulfate polyacrylamide gel electrophoresis; Tris: tris(hydroxymethyl)-aminomethan; Wt: wildtype; zVAD-fmk: (N-CBZ-Val-AalAsp(O-Me) fluoromethyl ketone.

\section{Competing interests}

The authors declare that they have no competing interests.

\section{Authors' contributions}

$\mathrm{HZ}$ contributed to conception and design, acquisition of data, analysis and interpretation of data and wrote the manuscript. AW contributed to conception, analysis and interpretation of data. RB carried out the quantitative RT-PCR and designed siRNA. NZ participated in the design of the study. GH conceived of the study, and participated in its design and coordination and wrote the manuscript. All authors read and approved the final manuscript.

\section{Acknowledgements}

This work was supported by the Deutsche Krebshilfe, Mildred Scheel-Stiftung We are grateful to Dr. Saul Rosenberg and Dr. Steve Elmore, Abbott Laboratories, for providing ABT-737.

\section{Author Details}

${ }^{1}$ Institute for Medical Microbiology, Technische Universität München, Trogerstr., Munich, Germany, 2Department of Dermatology and Allergology, LudwigMaximilian University, Frauenlobstr., Munich, Germany, ${ }^{3}$ Clinic of Urology, Clinic Konstanz, Luisenstr., Konstanz, Germany and 4 Institute of Medical Microbiology and Hygiene, University Freiburg, Hermann-Herder-Str., Freiburg, Germany

Received: 12 January 2010 Accepted: 24 June 2010

Published: 24 June 2010

\section{References}

1. Mickisch GH: Principles of nephrectomy for malignant disease. BJU Int 2002, 89:488-495.

2. Janzen NK, Kim HL, Figlin RA, Belldegrun AS: Surveillance after radical or partial nephrectomy for localized renal cell carcinoma and management of recurrent disease. Urol Clin North Am 2003, 30:843-852.

3. Youle RJ, Strasser A: The BCL-2 protein family: opposing activities that mediate cell death. Nat Rev Mol Cell Biol 2008, 9:47-59.
4. Cory S, Adams JM: Killing cancer cells by flipping the Bcl-2/Bax switch. Cancer Cell 2005, 8:5-6.

5. Kuwana T, Bouchier-Hayes L, Chipuk JE, Bonzon C, Sullivan BA, Green DR, Newmeyer DD: BH3 domains of $\mathrm{BH} 3$-only proteins differentially regulate Bax-mediated mitochondrial membrane permeabilization both directly and indirectly. Mol Cell 2005, 17:525-535.

6. Willis SN, Fletcher Jl, Kaufmann T, van Delft MF, Chen L, Czabotar PE, lerino H, Lee EF, Fairlie WD, Bouillet P, Strasser A, Kluck RM, Adams JM, Huang DC: Apoptosis initiated when $\mathrm{BH} 3$ ligands engage multiple $\mathrm{BCl}-2$ homologs, not Bax or Bak. Science 2007, 315:856-859.

7. Kim H, Rafiuddin-Shah M, Tu HC, Jeffers JR, Zambetti GP, Hsieh JJ, Cheng EH: Hierarchical regulation of mitochondrion-dependent apoptosis by BCL-2 subfamilies. Nat Cell Biol 2006, 8:1348-1358.

8. Chen L, Willis SN, Wei A, Smith BJ, Fletcher Jl, Hinds MG, Colman PM, Day $\mathrm{CL}$, Adams JM, Huang DC: Differential targeting of prosurvival BCl-2 proteins by their $\mathrm{BH} 3$-only ligands allows complementary apoptotic function. Mol Cell 2005, 17:393-403.

9. Letai A, Bassik MC, Walensky LD, Sorcinelli MD, Weiler S, Korsmeyer SJ: Distinct $\mathrm{BH} 3$ domains either sensitize or activate mitochondrial apoptosis, serving as prototype cancer therapeutics. Cancer Cell 2002, 2:183-192.

10. Hacker $\mathrm{G}$, Weber $\mathrm{A}: \mathrm{BH}$ 3-only proteins trigger cytochrome c release, but how? Arch Biochem Biophys 2007, 462:150-155

11. Oltersdorf T, Elmore SW, Shoemaker AR, Armstrong RC, Augeri DJ, Belli BA, Bruncko M, Deckwerth TL, Dinges J, Hajduk PJ, Joseph MK, Kitada S, Korsmeyer SJ, Kunzer AR, Letai A, Li C, Mitten MJ, Nettesheim DG, Ng S, Nimmer PM, O'Connor JM, Oleksijew A, Petros AM, Reed JC, Shen W, Tahir SK, Thompson CB, Tomaselli KJ, Wang B, Wendt MD, et al: An inhibitor of $\mathrm{BCl}-2$ family proteins induces regression of solid tumours. Nature 2005, 435:677-681.

12. Fesik SW: Promoting apoptosis as a strategy for cancer drug discovery. Nat Rev Cancer 2005, 5:876-885.

13. Tse C, Shoemaker AR, Adickes J, Anderson MG, Chen J, Jin S, Johnson EF, Marsh KC, Mitten MJ, Nimmer P, Roberts L, Tahir SK, Xiao Y, Yang X, Zhang $H$, Fesik S, Rosenberg SH, Elmore SW: ABT-263: a potent and orally bioavailable Bcl-2 family inhibitor. Cancer Res 2008, 68:3421-3428.

14. van Delft MF, Wei AH, Mason KD, Vandenberg CJ, Chen L, Czabotar PE, Willis SN, Scott CL, Day CL, Cory S, Adams JM, Roberts AW, Huang DC: The $\mathrm{BH} 3$ mimetic $\mathrm{ABT}-737$ targets selective $\mathrm{BCl}-2$ proteins and efficiently induces apoptosis via Bak/Bax if Mcl-1 is neutralized. Cancer Cell 2006 10:389-399.

15. Adams JM, Cory S: Bcl-2-regulated apoptosis: mechanism and therapeutic potential. Curr Opin Immunol 2007, 19:488-496.

16. Dai Y, Grant S: Targeting multiple arms of the apoptotic regulatory machinery. Cancer Res 2007, 67:2908-2911.

17. Vogler M, Butterworth M, Majid A, Walewska RJ, Sun XM, Dyer MJ, Cohen GM: Concurrent upregulation of BCL-XL and BCL2A1 induces 1000fold resistance to ABT-737 in chronic lymphocytic leukemia. Blood 2008, 30;113(18):5828-5832.

18. Brien G, Trescol-Biemont MC, Bonnefoy-Berard N: Downregulation of Bfl1 protein expression sensitizes malignant $B$ cells to apoptosis. Oncogene 2007, 26:5828-5832.

19. Simmons MJ, Fan G, Zong WX, Degenhardt K, White E, Gelinas C: Bfl-1/A1 functions, similar to $\mathrm{Mcl}-1$, as a selective tBid and Bak antagonist. Oncogene 2008, 27:1421-1428.

20. Whitecross KF, Alsop AE, Cluse LA, Wiegmans A, Banks KM, Coomans C, Peart MJ, Newbold A, Lindemann RK, Johnstone RW: Defining the target specificity of ABT-737 and synergistic antitumor activities in combination with histone deacetylase inhibitors. Blood 2009, 113:1982-1991.

21. Huang A, Fone PD, Gandour-Edwards R, White RW, Low RK: Immunohistochemical analysis of $\mathrm{BCL}-2$ protein expression in renal cell carcinoma. J Urol 1999, 162:610-613.

22. Kallio JP, Hirvikoski P, Helin H, Luukkaala T, Tammela TL, KellokumpuLehtinen P, Martikainen PM: Renal Cell Carcinoma Mib-1, Bax And Bcl-2 Expression And Prognosis. J Urol 2004, 172:2158-2161.

23. Zantl N, Weirich G, Zall H, Seiffert BM, Fischer SF, Kirschnek S, Hartmann C, Fritsch RM, Gillissen B, Daniel PT, Hacker G: Frequent loss of expression of the pro-apoptotic protein Bim in renal cell carcinoma: evidence for contribution to apoptosis resistance. Oncogene 2007, 26:7038-7048. 
24. Giam $M$, Huang DC, Bouillet P: BH3-only proteins and their roles in programmed cell death. Oncogene 2008, 27(Suppl 1):S128-136.

25. van Delft MF, Huang DC: How the Bcl-2 family of proteins interact to regulate apoptosis. Cell Res 2006, 16:203-213.

26. Cragg MS, Jansen ES, Cook M, Harris C, Strasser A, Scott CL: Treatment of B-RAF mutant human tumor cells with a MEK inhibitor requires Bim and is enhanced by a BH3 mimetic. J Clin Invest 2008, 118:3651-3659.

27. Vaux DL: ABT-737, proving to be a great tool even before it is proven in the clinic. Cell Death Differ 2008, 15:807-808

28. Labi V, Grespi F, Baumgartner F, Villunger A: Targeting the Bcl-2regulated apoptosis pathway by $\mathrm{BH} 3$ mimetics: a breakthrough in anticancer therapy? Cell Death Differ 2008, 15:977-987.

29. Hijikata M, Kato N, Sato T, Kagami Y, Shimotohno K: Molecular cloning and characterization of a CDNA for a novel phorbol-12-myristate-13acetate-responsive gene that is highly expressed in an adult T-cell leukemia cell line. J Virol 1990, 64:4632-4639.

30. Oda E, Ohki R, Murasawa H, Nemoto J, Shibue T, Yamashita T, Tokino T, Taniguchi T, Tanaka N: Noxa, a BH3-only member of the Bcl-2 family and candidate mediator of p53-induced apoptosis. Science 2000, 288:1053-1058

31. Lallemand C, Blanchard B, Palmieri M, Lebon P, May E, Tovey MG: Singlestranded RNA viruses inactivate the transcriptional activity of $\mathrm{p} 53$ but induce NOXA-dependent apoptosis via post-translational modifications of IRF-1, IRF-3 and CREB. Oncogene 2007, 26:328-338.

32. Sun Y, Leaman DW: Involvement of Noxa in cellular apoptotic responses to interferon, double-stranded RNA, and virus infection. J Biol Chem 2005, 280:15561-15568.

33. Nikiforov MA, Riblett M, Tang WH, Gratchouck V, Zhuang D, Fernandez Y, Verhaegen M, Varambally S, Chinnaiyan AM, Jakubowiak AJ, Soengas MS Tumor cell-selective regulation of NOXA by c-MYC in response to proteasome inhibition. Proc Natl Acad Sci USA 2007, 104:19488-19493.

34. Gurova KV, Hill JE, Razorenova OV, Chumakov PM, Gudkov AV: p53 pathway in renal cell carcinoma is repressed by a dominant mechanism. Cancer Res 2004, 64:1951-1958.

35. Gurova KV, Hill JE, Guo C, Prokvolit A, Burdelya LG, Samoylova E, Khodyakova AV, Ganapathi R, Ganapathi M, Tararova ND, Bosykh D, Lvovskiy D, Webb TR, Stark GR, Gudkov AV: Small molecules that reactivate $p 53$ in renal cell carcinoma reveal a NF-kappaB-dependent mechanism of $\mathrm{p} 53$ suppression in tumors. Proc Natl Acad Sci USA 2005, 102:17448-17453.

36. Tang SW, Chang WH, Su YC, Chen YC, Lai YH, Wu PT, Hsu CI, Lin WC, Lai MK, Lin JY: MYC pathway is activated in clear cell renal cell carcinoma and essential for proliferation of clear cell renal cell carcinoma cells. Cancer Lett 2009, 273:35-43.

37. Willis SN, Chen L, Dewson G, Wei A, Naik E, Fletcher JI, Adams JM, Huang DC: Proapoptotic Bak is sequestered by Mcl-1 and Bcl-xL, but not Bcl-2, until displaced by BH3-only proteins. Genes Dev 2005, 19:1294-1305.

doi: $10.1186 / 1476-4598-9-164$

Cite this article as: Zall et al., Chemotherapeutic drugs sensitize human renal cell carcinoma cells to ABT-737 by a mechanism involving the Noxadependent inactivation of Mcl-1 or A1 Molecular Cancer 2010, 9:164

\section{Submit your next manuscript to BioMed Central} and take full advantage of:

- Convenient online submission

- Thorough peer review

- No space constraints or color figure charges

- Immediate publication on acceptance

- Inclusion in PubMed, CAS, Scopus and Google Scholar

- Research which is freely available for redistribution

Submit your manuscript at www.biomedcentral.com/submit
C Biomed Central 